\title{
The Effect of Age on Subfoveal Choroidal Thickness
}

\section{in Healthy Subjects}

\author{
Kamil Yavuzer $^{1^{\star}}$, Banu Bozkurt ${ }^{2}$, Banu Turgut Ozturk ${ }^{2}$, Suleyman Okudan ${ }^{2}$ \\ ${ }^{1}$ University of Health Sciences, Van Training and Research Hospital, Ophthalmology Clinic, Van, Turkey \\ 2 Selcuk University, Faculty of Medicine, Department of Ophthalmology, Konya, Turkey
}

\begin{abstract}
To assess the normative values of subfoveal choroidal thickness (SFCT) in healthy Turkish subjects using spectral-domain optical coherence tomography (SD-OCT, Spectralis ${ }^{\circledR}$, Heidelberg Engineering, Germany) and its relationship with age and gender.

One hundred sixty-nine emmetropic healthy subjects (84 men; 49.7\%, 85 women 50.3\%) underwent a detailed ophthalmological examination. The subjects were divided into 5 groups according to age; Group 1 ( $\mathrm{n}=42$ ): 18-29 years, group $2(\mathrm{n}=34): 30-39$ years, group $3(\mathrm{n}=33): 40-49$ years, group $4(\mathrm{n}=34): 50-59$ years, group $5(\mathrm{n}=26): 60$ years and older.

There were statistically significant differences in mean SFCT values among different age groups ( $\mathrm{p}<0.05)$. Mean SFCT was highest in subjects under 30 years $(364.87 \pm 71.24 \mu \mathrm{m})$ and lowest in subjects over 60 years $(261.25 \pm 52.39 \mu \mathrm{m})$. There was a statistically significant negative correlation between age and SFCT values $(r=-0.52, p<0.001)$. Slope of change in SFCT over time in the subjects was $-2.59 \mu \mathrm{m}$ per year. When all subjects were evaluated, the mean SFCT value was 322.73 $\pm 64.00 \mu \mathrm{m}$ in men and $310.47 \pm 60.11 \mu \mathrm{m}$ in women $(\mathrm{p}=0.34)$. Except group 4 , SFCT did not differ between men and women.

SFCT decreases with aging and sex does not seem to alter the measurements. Our normative data according to age groups and gender might be used to demonstrate SFCT changes in various retinal and choroidal diseases in Turkish population.
\end{abstract}

Keywords: Age, gender, healthy subjects, optical coherence tomography, subfoveal choroidal thickness

\section{Introduction}

Choroid is one of the most highly vascularized tissues of the body, located between retina and sclera (1). Oxygen and nutrient supply of the outer retinal segments, including photoreceptors, are provided from the choroid (2). Structural or functional disorders of the choroid may affect the retinal and the visual functions (1-2). Optical coherence tomography (OCT) is a fast, noninvasive and non-contact measurement device that provides high resolution and cross-sectional images of the retina using light waves (3). It is widely used in the diagnosis and follow-up of several retinal and optic nerve disorders such as age-related macular degeneration, macular edema, and glaucoma (4). The OCT device provides many measurements, such as retinal nerve fiber layer (RNFL) thickness, optic nerve head parameters (cupping, neuroretinal rim) or macular retinal thickness (5). Choroid, which has a dynamic structure, has been evaluated in-vivo with the enhanced depth imaging (EDI) method that has been recently used for clinical purposes. Choroid plays a key role in the pathophysiology of chorioretinal disorders, such as central serous chorioretinopathy, age-related macular degeneration, and Vogt-Koyanagi-Harada disease and in the literature, there are many studies on choroidal thickness measurements in health and diseases (6-10). Many factors have been shown to affect choroidal thickness, such as axial length, refractive error, amblyopia, puberty, pregnancy, thyroid disease and drug use (11-16).

The aim of the present study is to establish a normative database for subfoveal choroid thickness (SFCT) measurements in healthy Turkish subjects using spectral-domain OCT (SD-OCT, Spectralis ${ }^{\circledR}$, Heidelberg Engineering, Heidelberg, Germany) and evaluate its relationship with age and gender.

\footnotetext{
${ }^{*}$ Corresponding Author: Kamil Yavuzer, University of Health Sciences, Van Training and Research Hospital, Ophthalmology Clinic, Van, Turkey 


\section{Materials and Methods}

The local ethics committee approval was obtained. Written informed consent was obtained from all subjects and the principles of the Helsinki Declaration were followed throughout the study. In this cross-sectional study, healthy volunteers who had no ocular disease other than minor refractive errors $(>-1.00 \mathrm{D}$ or $<+1.00 \mathrm{D})$ were included. Those with systemic diseases such as diabetes mellitus and hypertension and those with a history of drug, cigarette, and alcohol use that may affect the retina and the choroidal thickness were excluded. The subjects with a history of ocular surgery, refractive spheric error $>1.00 \mathrm{D}$, anisometropia, astigmatism above $1.50 \mathrm{D}$, those with poor OCT scans that obscure the evaluation of the choroidal borders were also excluded.

All patients were examined between 9:00 am and 10:00 am to exclude diurnal variation. Choroidal imaging was performed as a single horizontal line scan passing through the fovea in the EDI mode of the OCT device (Spectralis ${ }^{\circledR}$, Heidelberg Engineering, Heidelberg, Germany). During the measurement, the OCT scans were carried out from the same section through the eye-tracking program, and the number of repetitive scanning was set to 100. Choroidal thickness was measured manually as the distance between the outer border of the hyper-reflective retinal pigment epithelium and the choroid/sclera junction from the subfoveal region using the program of the device (Figure 1). Multiple OCT scans were obtained by a technician. Those with poor image quality were excluded and the best one was used included in the study. The SFCT measurement was done by the same investigator.

Spectralis ${ }^{\circledR}$ OCT usually takes $6 \times 6 \mathrm{~mm}$ square sections centered on the fovea. In images taken in EDI mode, the device head is brought closer to the eye, and the reverse image that is normally not reflected on the screen is reflected on the screen. In this way, the deep choroidal parts approach the zero-delay line and thus the inverted image provides more information for the choroidal structures than the normal flat image. The system has a dual laser scanner system that simultaneously provides cross-section and reference scanning. From the reference points determined from the image obtained by cross-sectional scanning; fundus fluorescein angiography, indocyanine green angiography, infrared image, fundus autofluorescence or red-free images can be created. SD-OCT that is performing 40,000 Ascans per second is integrated into the system.
While the resolution level is $14 \mu \mathrm{m}$ in transverse sections, this value is $7 \mu \mathrm{m}$ in axial sections. Thanks to five different imaging modes obtained by reference scanning, it is possible to determine different anatomical features with different wavelengths. At the same time, a more detailed choroidal image is obtained by taking multiple scans from the same area using eye tracking system and improving signal-to-noise ratio.

The subjects were divided into 5 groups according to their age ranges; group $1(\mathrm{n}=42), 18-29$ years; group $2(\mathrm{n}=34), 30-39$ years; group $3(\mathrm{n}=33)$, 40-49 years; group $4(\mathrm{n}=34): 50-59$ age; group 5 $(n=26), 60$ years and older. The obtained data were coded and transferred to the computer program.

Statistical Analysis: Descriptive statistics for the studied variables were presented as Mean and Standard Deviation Normality assumption of the variables was tested with Kolmogov-Smirnov test. In order to compare independent and dependent groups independent $\mathrm{t}$ test and Paired $\mathrm{t}$ tests were performed for the normally distributed variables. In addition, one-way ANOVA test was used to determine the differences in choroidal thickness between the groups. If there was statistical significance, Duncan, a post hoc test, was used for pairwise group comparisons. Pearson correlation test was used to analyze the relationship between choroidal thickness and age. Statistical significance level was considered as 5\% and SPSS (ver: 18) statistical program was used for all statistical computations.

\section{Results}

One hundred and sixty-nine healthy volunteers between the ages of 18-72 years were included in the study. Eighty-four (49.7\%) were men and 85 $(50.3 \%)$ were women. There was no statistically significant difference in terms of gender by age groups $(p=0.96)$. The mean ages of men and women were $41.09 \pm 14.16$ and $41.78 \pm 14.89$ years, respectively $(p=0.26)$. The demographic characteristics of the participants of the study are given in Table 1.

Mean SFCT values in the right and left eyes were $314.34 \pm 71.37 \mu \mathrm{m}$ and $319.82 \pm 76.03 \mu \mathrm{m}$, respectively $(\mathrm{p}=0.14)$. There were statistically significant differences in mean SFCT values among different age groups (range 138-537 $\mu \mathrm{m})(\mathrm{p}$ $<0.001$ ) (Table 2). Mean SFCT was highest in subjects under 30 years $(364.87 \pm 71.24 \mu \mathrm{m})$ and lowest in subjects over 60 years $(261.25 \pm 52.39$ $\mu \mathrm{m})$. In each decade over the age of 18 ,

East J Med Volume:26, Number:4, October-December/2021 
Table 1. Demographic Characteristics of The Groups

\begin{tabular}{lcccccc}
\hline Groups & Case $(\mathrm{n})$ & $\begin{array}{c}\text { Age range } \\
\text { (years) }\end{array}$ & \multicolumn{2}{c}{ Men } & \multicolumn{2}{c}{ Women } \\
\cline { 4 - 7 } & & $18-29$ & $21(50)$ & $23.14 \pm 3.52$ & $21(50)$ & $23.14 \pm 3.54$ \\
\hline 1 & 42 & $30-39$ & $17(50)$ & $34.12 \pm 2.93$ & $17(50)$ & $34.12 \pm 3.05$ \\
2 & 34 & $40-49$ & $16(48.5)$ & $44.38 \pm 3.1$ & $17(51.5)$ & $44.59 \pm 2.49$ \\
3 & 33 & $50-59$ & $18(52.9)$ & $54.44 \pm 3.08$ & $16(47.1)$ & $53.5 \pm 2.92$ \\
4 & 34 & $60-73$ & $12(46.2)$ & $64.42 \pm 3.72$ & $14(53.8)$ & $63.71 \pm 3.18$ \\
5 & 26 & $18-72$ & $84(49.7)$ & $41.09 \pm 14.16$ & $85(50.3)$ & $41.78 \pm 14.89$ \\
\hline
\end{tabular}

SD: Standard Deviation

Table 2. The Comparison of the Mean Subfoveal Choroidal Thickness Between Groups

\begin{tabular}{|c|c|c|c|c|c|c|c|}
\hline & & Mean & Std. Dev. & SE & Min. & Max. & $\mathrm{p} \#$ \\
\hline \multirow[t]{6}{*}{ SFCTright } & 1 & $361,74 a$ & 67,25 & 10,38 & 217,00 & 537,00 & 0,001 \\
\hline & 2 & $331,24 b$ & 77,00 & 13,20 & 193,00 & 468,00 & \\
\hline & 3 & $309,85 c$ & 60,05 & 10,45 & 189,00 & 430,00 & \\
\hline & 4 & $278,88 \mathrm{c}$ & 51,29 & 8,80 & 179,00 & 382,00 & \\
\hline & 5 & $266,50 c$ & 49,56 & 9,72 & 138,00 & 354,00 & \\
\hline & Total & 314,15 & 71,20 & 5,48 & 138,00 & 537,00 & \\
\hline \multirow[t]{6}{*}{ SFCT left } & 1 & $368,00 \mathrm{a}$ & 75,71 & 11,68 & 200,00 & 516,00 & 0,001 \\
\hline & 2 & $341,38 \mathrm{ab}$ & 75,53 & 12,95 & 182,00 & 465,00 & \\
\hline & 3 & $318,06 b$ & 67,01 & 11,67 & 172,00 & 434,00 & \\
\hline & 4 & $285,06 \mathrm{c}$ & 49,52 & 8,49 & 200,00 & 385,00 & \\
\hline & 5 & $256,00 \mathrm{c}$ & 55,55 & 10,90 & 153,00 & 351,00 & \\
\hline & Total & 318,98 & 76,58 & 5,89 & 153,00 & 516,00 & \\
\hline \multicolumn{8}{|c|}{$\mathrm{p}$ value (For group 1: right vs left) $=0,402$ (Paired $\mathrm{t}$ test) } \\
\hline \multicolumn{8}{|c|}{$\mathrm{p}$ value (For group 2: right vs left) $=0,144$ (Paired t test) } \\
\hline \multicolumn{8}{|c|}{$\mathrm{p}$ value (For group 3: right vs left) $=0,341$ (Paired t test) } \\
\hline \multicolumn{8}{|c|}{$\mathrm{p}$ value (For group 4: right vs left) $=0,358$ (Paired t test) } \\
\hline \multicolumn{8}{|c|}{$\mathrm{p}$ value (For group 5: right vs left) $=0,120$ (Paired t test) } \\
\hline
\end{tabular}

$\mathbf{a}, \mathbf{b}, \mathbf{c}, \mathbf{d} \downarrow$ : Different lower letters represent statistically significant differences among the groups in right and left side (Duncan test)

\#: One-way ANOVA

approximately $25 \mu \mathrm{m}$ choroidal thinning was observed. Slope of change in SFCT over time in the subjects was $-2.59 \mu \mathrm{m}$ per year. There was a statistically significant negative correlation between age and SFCT $(\mathrm{r}=-0.517, \mathrm{p}<0.001)$ (Figure 2). In pairwise group comparisons, there was a statistically significant difference between groups 1 and groups 3,4 and 5 ( $p<0.001$ for all); between group 2 and groups 4 and 5 ( $p<0.001$ for all); between group 3 and groups 1, 4 and 5 (p $<0.001, \mathrm{p}=0.034, \mathrm{p}<0.001$, respectively). When all subjects were evaluated, the mean SFCT value was $322.73 \pm 64.00 \mu \mathrm{m}$ in men and $310.47 \pm 60.11$ $\mu \mathrm{m}$ in women $(\mathrm{p}=0.343)$. Except group 4 , SFCT did not differ between men and women (Table 3 ).

\section{Discussion}

In this study, we evaluated the effect of age and gender on SFCT in healthy subjects to establish a normative database to be used in further investigations. In the literature, the age is the most studied factor in its relationship with choroidal thickness. In an autopsy study by Ramrattan et al. (17), the mean choroidal thickness was found to be $193.5 \mu \mathrm{m}$ in the first decade and $84 \mu \mathrm{m}$ in the $10^{\text {th }}$ decade. However, the choroidal thickness measurements in histopathological studies may not fully reflect the real values, since fixation processes, shrinkage and tissue damage and cessation of circulation after death might cause alterations in the choroidal thickness (18-19). 
Yavuzer et al / Effect of Age on Choroidal Thickness

Table 3. Descriptive Statistics and Comparison Results For Gender

\begin{tabular}{lccccccc}
\hline & Gender & Mean & SE & Std. Dev. & Min. & Max. & p \# \\
\hline SFCTright & Male & 319,64 & 8,10 & 74,22 & 138,00 & 537,00 & 0,320 \\
& Female & 308,72 & 7,38 & 68,08 & 179,00 & 496,00 & \\
SFCT left & Male & 325,81 & 8,55 & 78,40 & 153,00 & 516,00 & 0,250 \\
& Female & 312,22 & 8,09 & 74,59 & 162,00 & 496,00 & \\
p value (For men: right vs left) $=0,219$ (Paired t test) & & & & \\
p value (For women: right vs left) & $=0,421$ (Paired t test) & & & \\
\hline
\end{tabular}

\#: Independent samples t test

Table 4. The Mean Subfoveal Choroidal Thickness (Sfct) Of Healthy Eyes In Published Literature With Different OCT Devices

\begin{tabular}{|c|c|c|c|c|c|c|}
\hline Study & $\begin{array}{l}\text { Used } \\
\text { method }\end{array}$ & $\begin{array}{c}\mathrm{n} \\
\text { (case) }\end{array}$ & $\begin{array}{c}\mathrm{n} \\
\text { (eyes) }\end{array}$ & $\begin{array}{c}\text { Age range } \\
\text { (years) }\end{array}$ & $\begin{array}{l}\text { Mean age } \\
\text { (years) }\end{array}$ & $\mathrm{SFCT}(\mu \mathrm{m})$ \\
\hline Spaide et al.20 & Spectralis ${ }^{\circledR}$ & 17 & 34 & $19-54$ & 33.4 & $\begin{array}{c}\text { right } 318 \\
\text { left } 335\end{array}$ \\
\hline Rahman et al.21 & Spectralis ${ }^{\circledR}$ & 50 & 100 & $30-49$ & $38 \pm 5$ & $\begin{array}{c}\text { right } 332 \pm 90 \\
\text { left } 332 \pm 91\end{array}$ \\
\hline Gök et al.22 & Spectralis ${ }^{\circledR}$ & 239 & 478 & $10-83$ & $\begin{array}{l}42.08 \\
\pm 20.87\end{array}$ & $334.59 \pm 64.60$ \\
\hline Margolis et al.23 & Spectralis ${ }^{\circledR}$ & 30 & 54 & $19-85$ & 50.4 & $287 \pm 76$ \\
\hline Noori et al.24 & Spectralis ${ }^{\circledR}$ & 32 & - & - & 65.81 & $248.93 \pm 50.92$ \\
\hline $\begin{array}{l}\text { Pongsachareonnont } \\
\text { et al. } 25\end{array}$ & $\begin{array}{l}\text { DRI-OCT } \\
\text { Triton }^{\mathrm{TM}}\end{array}$ & 144 & 144 & $18-85$ & $41 \pm 13$ & $326.0 \pm 86.2$ \\
\hline Bhayana et al.26 & $\begin{array}{l}\text { DRI-OCT } \\
\text { Triton Plus }\end{array}$ & 119 & 238 & $19-60$ & $\begin{array}{l}28.70 \\
\pm 11.28\end{array}$ & $299.10 \pm 131.2$ \\
\hline Ikuno et al.28 & $\begin{array}{l}1060 \mathrm{~nm} \\
\text { OCT }\end{array}$ & 43 & 86 & $23-88$ & $\begin{array}{c}39.4 \\
\pm 16.0\end{array}$ & $354 \pm 111$ \\
\hline Manjunath et al.29 & $\begin{array}{l}\text { Cirrus }{ }^{\circledR} \\
\text { HD-OCT }\end{array}$ & 34 & 34 & $22-78$ & 51.1 & $272 \pm 81$ \\
\hline Our Study & Spectralis ${ }^{\circledR}$ & 169 & 338 & $18-72$ & $\begin{array}{l}41.45 \\
\pm 14.22\end{array}$ & $\begin{array}{c}\text { right } 314.34 \\
\pm 71.37 \\
\text { left } 319.82 \pm 76.09\end{array}$ \\
\hline
\end{tabular}

$\mu \mathrm{m}:$ micrometer

In our study, mean SFCT measurements taken with the EDI mode of the Spectralis ${ }^{\circledR}$ (Heidelberg Engineering) were $314.34 \pm 71.37 \mu \mathrm{m}$ in the right eye and $319.82 \pm 76.03 \mu \mathrm{m}$ in the left eye within a range of 138-537 $\mu \mathrm{m}$. Mean SFCT values differed remarkably among different age groups $(\mathrm{p}<0.05)$, being highest in subjects under 30 years $(364.87 \pm$ $71.24 \mu \mathrm{m})$ and lowest in subjects over 60 years $(261.25 \pm 52.39 \mu \mathrm{m})$. The correlation between age and SFCT values was remarkable $(r=-0.52, p$ $<0.001)$. Slope of change in SFCT over time was $2.59 \mu \mathrm{m}$ per year. Using the same device, Spaide et al. (20) found the mean SFCT value of the right and left eyes of 17 healthy subjects with a mean age of 33.4 years as $318 \mu \mathrm{m}$ and $335 \mu \mathrm{m}$. Similarly, in the study performed by Rahman et al. (21), the mean values of SFCT were $332 \pm 90 \mu \mathrm{m}$ in the right eyes and $332 \pm 91 \mu \mathrm{m}$ in the left eyes of 50 healthy individuals with a mean age of $38 \pm 5$ years. The mean age of group 2 in our study was $34.12 \pm 2.92$ years and the mean SFCT value was $336.31 \pm 75.87 \mu \mathrm{m}$, which was comparable to the studies of Spaide (20) and Rahman (21). In the study of Gök et al. (22) on 239 patients with same SD-OCT device, the mean age was $42.08 \pm 20.87$ years and the mean SFCT value was $334.59 \pm$ 64.60 $\mu \mathrm{m}$, which was higher than our population, although the mean ages were similar. In the study

East J Med Volume:26, Number:4, October-December/2021 


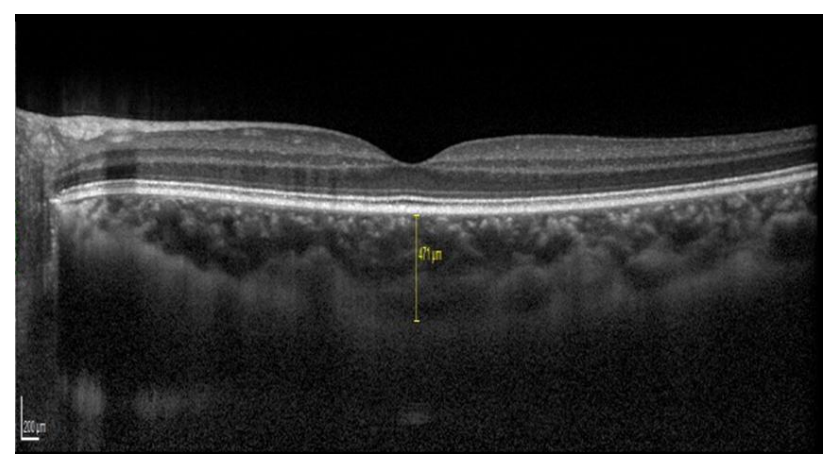

Fig. 1. Manual Measurement of SFCT in Oct Image Obtained By EDI Mode of The Spectralis ${ }^{\circledR}$ Device

of Margolis and Spaide (23), the mean SFCT value was $287 \pm 76 \mu \mathrm{m}$ in individuals with a mean age of 50.4 years, which was similar with group 4 (5059 years). In the study of Noori et al. (24), mean SFCT was $248.93 \pm 50.92 \mu \mathrm{m}$ in healthy individuals with a mean age of 65.81 years, similar with group 5 with a mean SFCT value of $261.25 \pm$ $52.391 \mu \mathrm{m}$. The details of the studies measuring SFCT via Spectralis SD-OCT in the literature were given in Table 4.

In many studies done with swept-source OCT (SSOCT), a negative correlation has been reported between age and SFCT (25-26). In the study of Pongsachareonnont et al. (25), mean SFCT was found to be $326.0 \pm 86.2 \mu \mathrm{m}$. Women comprised the majority $(80 \%)$ of the cases. SFCT was negatively correlated with age $(\mathrm{r} 2=0.097, \mathrm{p}$ $<0.001$ ) and was found to be decreased by $1.5 \mu \mathrm{m}$ with each year. This study is similar with our study in terms of age. In the study of Bhayana et al. (26) mean SFCT was found to be $299.10 \pm 131.2 \mu \mathrm{m}$ in a group of patients with a mean age of $28.70 \pm$ 11.28 years (19-60 years). There was no statistically significant correlation between age and SFCT $(\mathrm{r}=-0.096, \mathrm{p}=0.139)$, while the correlation between axial length and SFCT was remarkable. In healthy eyes, Philip et al. (27) showed a high correlation between SD-OCT and SS-OCT measurements. SD-OCT measurements were higher than SS-OCT measurements. SS-OCT that uses a $1050-\mathrm{nm}$ wavelength light source is superior to SD-OCT. The visualization of structures beneath the RPE is much better with SS-OCTdue to decreased sensitivity roll-off and attenuation of the OCT signal in deeper structures, particularly the choroid. In SD-OCT system, $840 \mathrm{~nm}$ light source does not allow deep penetration and light scattering is greater. In another study performed with a $1060 \mathrm{~nm}$ OCT device, age was found to be the most associated factor with choroidal thickness (28). In the study of Manjunath et al. (29), mean SFCT measured with Cirrus ${ }^{\circledR}$ HD-OCT was $272 \pm 81 \mu \mathrm{m}$ in a

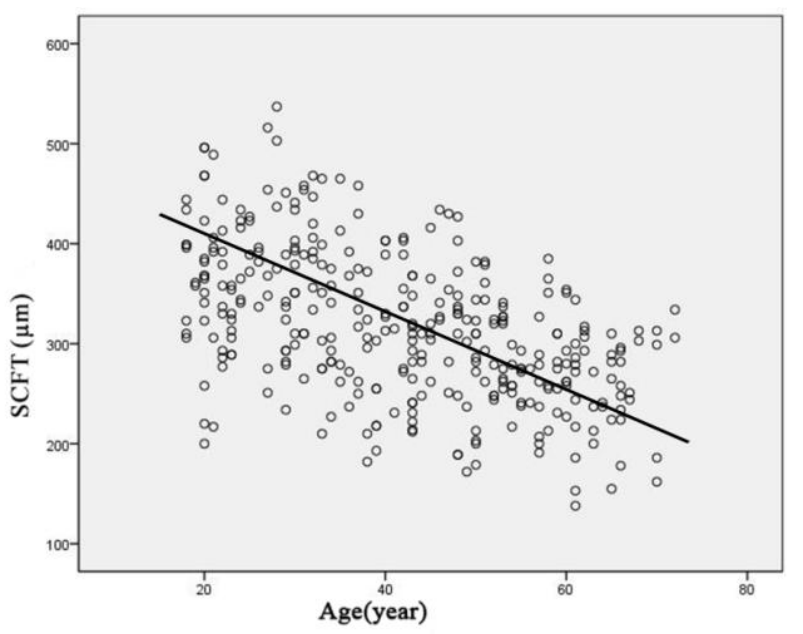

Fig. 2. Scatter/Dot Graph Showing The Subfoveal Choroidal Thickness (SFCT) Distribution By Age

study group with a mean age of 51.1 years. The authors found a negative correlation between age and SFCT. The details of the studies in the literature were given in Table 4.

In the literature, there are studies which evaluate the relationship between gender and choroid thickness (30-34). In the study of $\mathrm{Li}$ et al. (30) mean SFCT was $62 \mu \mathrm{m}$ thicker in males than females. Ding et al. (31) reported higher SFCT values in males $(270 \mu \mathrm{m})$ compared to females $(254 \mu \mathrm{m})(\mathrm{p}=0.057)$. Barteselli et al. (32) found the mean central choroidal volume as $7.664 \pm$ $2.283 \mathrm{~mm} 3$ in males and as $7.138 \pm 2.077 \mathrm{~mm} 3$ in females ( $\mathrm{p}<0.05$ ), while Kim et al. (33) and Fujiwara et al. (34) did not find any difference in SFCT between men and women $(p>0.05)$. In our study, mean SFCT did not differ statistically significant between men and women in age groups, expect group 4, in which mean SFCT was statistically significant higher in men (301.42 \pm 50.21) compared to women (260.09 \pm 40.66) $(\mathrm{p}<0.05)$.

In conclusion, SFCT decreases with aging and sex does not seem to alter SFCT measurements. Our results will provide useful data for further investigations in choroidal disorders. Our normative data according to age groups and gender might to be helpful to demonstrate SFCT changes in various retinal and choroidal diseases in Turkish population.

\section{References}

1. Çerman E, Çekiç O. The Thermoregulator the of Retina: the Choroid. Ret-Vit 2014; 22: 79-83.

2. Carbonell M, Alonso N, Castelblanco E, Real J, Ramírez-Morros A, Simó R, et al. Assessment of Inner Retinal Layers and Choroidal Thickness in 
Type 1 Diabetes Mellitus: A Cross-Sectional Study. J Clin Med 2019; 8:1412.

3. Podoleanu AG. Optical coherence tomography. J Microsc 2012; 247: 209-219.

4. Sakata LM, Deleon-Ortega J, Sakata V, Girkin CA. Optical coherence tomography of the retina and optic nerve - a review. Clin Exp Ophthalmol 2009; 37: 90-99.

5. Yeter V, Sayın O, Arıtürk N. Comparison of Macular, Retinal Nerve Fiber Layer, and Optic Disc Parameters between Children and Adults. Ret-Vit 2012; 20: 88-94.

6. Entezari M, Karimi S, Ramezani A, Nikkhah H, Fekri Y, Kheiri B. Choroidal Thickness in Healthy Subjects. J Ophthalmic Vis Res 2018; 13: 39-43.

7. Singh SR, Rasheed MA, Goud A, Sahoo NK, Vupparaboina KK, Chhablani J. Diurnal variation in subfoveal and peripapillary choroidal vascularity index in healthy eyes. Indian J Ophthalmol 2019; 67: 1667-1672.

8. Gemenetzi M, De Salvo G, Lotery AJ. Central serous chorioretinopathy: an update on pathogenesis and treatment. Eye (Lond) 2010; 24: 1743-1756.

9. Spaide RF. Age-related choroidal atrophy. Am J Ophthalmol 2009; 147: 801-810.

10. Maruko I, Iida T, Sugano Y, Oyamada H, Sekiryu T, Fujiwara T, et al. Subfoveal choroidal thickness after treatment of Vogt-Koyanagi-Harada disease. Retina 2011; 31: 510-517.

11. Sander BP, Collins MJ, Read SA. Short-Term Effect of Low-Dose Atropine and Hyperopic Defocus on Choroidal Thickness and Axial Length in Young Myopic Adults. J Ophthalmol 2019; 21: 4782536.

12. Qi Y, Li L, Zhang F. Choroidal Thickness in Chinese Children Aged 8 to 11 Years with Mild and Moderate Myopia. J Ophthalmol 2018; 31: 7270127.

13. Nishi $T$, Ueda $T$, Mizusawa $Y$, Semba $K$, Shinomiya K, Mitamura Y, et al. Effect of optical correction on subfoveal choroidal thickness in children with anisohypermetropic amblyopia. PLoS One 2017; 19: e0189735.

14. Ulusoy DM, Duru N, Ataş M, Altınkaynak H, Duru Z, Açmaz G. Measurement of choroidal thickness and macular thickness during and after pregnancy. Int J Ophthalmol 2015; 18: 321-325.

15. Ulas F, Dogan Ü, Dikbas O, Celebi S, Keles A. Investigation of the choroidal thickness in patients with hypothyroidism. Indian J Ophthalmol 2015; 63: 244-249.

16. Li XQ, Jeppesen $\mathrm{P}$, Larsen M, Munch IC. Subfoveal choroidal thickness in 1323 children aged 11 to 12 years and association with puberty: the Copenhagen Child Cohort 2000 Eye Study. Invest Ophthalmol Vis Sci 2014; 29: 550-555.

17. Ramrattan RS, van der Schaft TL, Mooy CM, de Bruijn WC, Mulder PG, de Jong PT. Morphometric analysis of Bruch's membrane, the choriocapillaris, and the choroid in aging. Invest Ophthalmol Vis Sci 1994; 35: 2857-2864.

18. Wang C, Ding Z, Geiser M, Wu T, Chen M. Choroidal laser Doppler Flowmeter with enhanced sensitivity based on a scattering plate. Journal of Biomedical Optics 2011; 16: 047004.

19. Skondra D, Papakostas T, Vavvas DG. Enhanced depth imaging optical coherence tomography in age-related macular degeneration. Semin Ophthalmol 2012; 27: 209-212.

20. Spaide RF, Koizumi H, Pozzoni MC. Enhanced depth imaging spectral-domain optical coherence tomography. Am J Ophthalmol 2008; 146: 496500.

21. Rahman W, Chen FK, Yeoh J, Patel P, Tufail A, D a Cruz L. Repeatability of manual subfoveal choroidal thickness measurements in healthy subject susing the technique of enhanced depth imaging optical coherence tomography. Invest Ophthalmol Vis Sci 2011; 52: 2267-2271.

22. Gök M, Aslan MŞ, Karabaş L. Evaluation of Choroidal Thickness by Using Optical Coherence Tomography in Healthy Individuals. Ret-Vit 2014; 22: 184-188.

23. Margolis R, Spaide RF. A pilot study of enhanced depth imaging optical coherence tomography of the choroid in normal eyes. Am J Ophthalmol 2009; 147: 811-815.

24. Noori J, RiaziEsfahani M, Hajizadeh F, Zaferani MM. Choroidal mapping; a novel approach for evaluating choroidal thickness and volume. J Ophthalmic Vis Res 2012; 7: 180-185.

25. Pongsachareonnont P, Somkijrungroj T, Assavapongpaiboon B, Chitamara T, Chuntarapas M, Suwajanakorn D. Foveal and parafoveal choroidal thickness pattern measuring by swept source optical coherence tomography. Eye (Lond) 2019; 33: 1443-1451.

26. Bhayana AA, Kumar V, Tayade A, Chandra M, Chandra P, Kumar A. Choroidal thickness in normal Indian eyes using swept-source optical coherence tomography. Indian J Ophthalmol 2019; 67: 252-255.

27. Philip AM, Gerendas BS, Zhang L, Faatz H, Podkowinski D, Bogunovic $\mathrm{H}$, et al. Choroidal thickness maps from spectral domain and swept source optical coherence tomography: algorithmic versus ground truth annotation. Br J Ophthalmol 2016; 100: 1372-1376.

28. Ikuno Y, Kawaguchi K, Nouchi T, Yasuno Y. Choroidal thickness in healthy Japanese subjects. Invest Ophthalmol Vis Sci 2010; 51: 2173-2176.

29. Manjunath V, Taha M, Fujimoto JG, Duker JS. Choroidal thickness in normal eyes measured using Cirrus HD optical coherence tomography. Am J Ophthalmol 2010; 150: 325-329.

30. Li XQ, Larsen M, Munch IC. Subfoveal choroidal thickness inrelation to sex and axial length in 93 Danish university students. Invest Ophthalmol Vis Sci 2011; 52: 8438-8441. 
31. Ding X, Li J, Zeng J, Ma W, Liu R, Li T, et al. Choroidal Thickness in Healthy Chinese Subjects. Invest Ophthalmol Vis Sci 2011; 52: 9555-9560.

32. Barteselli G, Chhablani J, El-Emam S, Wang H, Chuang J, Kozak I, et al. Choroidal volume variations with age, axial length, and sex in healthy subjects: a three-dimensional analysis. Ophthalmology 2012; 119: 2572-2578.

33. Kim SW, Oh J, Kwon SS, Yoo J, Huh K. Comparison of choroidal thickness among patients with healthy eyes, early age-related maculopathy, neovascular age-related macular degeneration, central serous chorioretinopathy, and polypoidal choroidal vasculopathy. Retina 2011; 31: 19041911.

34. Fujiwara A, Shiragami C, Shirakata Y, Manabe S, Izumibata S, Shiraga F. Enhanced depth imaging spectral-domain optical coherence tomography of subfoveal choroidal thickness in normal Japanese eyes. Jpn J Ophthalmol 2012; 56: 230-235. 